\title{
Glycemic Index of a Novel High-Fiber White Rice Variety Developed in India-A Randomized Control Trial Study
}

\author{
Viswanathan Mohan, MD, FRCP, PhD, DSc, Ranjit Mohan Anjana, PhD, Rajgopal Gayathri, MSc, \\ Mookambika Ramya Bai, MPhil, Nagrajan Lakshmipriya, MSc, Vaidya Ruchi, PhD, \\ K.K. Balasubramaniyam, MSc, M. Mohamed Jakir, MSc, Shanmugam Shobana, PhD, \\ Ranjit Unnikrishnan, MD, Kamala Krishnaswamy, PhD, Jeya Kumar Henry, PhD, \\ and Vasudevan Sudha, MSc ${ }^{2}$
}

\begin{abstract}
Background: White rice, a common Indian staple, has a high glycemic response and is associated with high risk of type 2 diabetes. The aim of this study was to compare the Glycemic Index (GI) of a newly developed highfiber white rice (HFWR) with that of commercial white rice (WR).

Materials and Methods: HFWR was developed using biochemical screening approaches and classical plant breeding techniques. The GI of HFWR was determined using a validated protocol in 30 healthy participants in the year 2013 and repeated in a subsample of 15 participants in the year 2014; the results were compared with the value for WR. The incremental area under the curve was calculated geometrically by applying the trapezoid rule for both reference food (glucose) and the test foods (HFWR and WR). Proximate principles along with dietary fiber, resistant starch, and amylose content were analyzed using standardized methods.

Results: The dietary fiber content of HFWR was fivefold higher $(8.0 \pm 0.1 \mathrm{vs.} 1.58 \pm 0.17 \mathrm{~g} \%)$, resistant starch content was 6.5 -fold higher $(3.9 \pm 0.2$ vs. $0.6 \pm 0.03 \mathrm{~g} \%)(P<0.001)$, and amylose content was significantly higher $(32.8 \pm 1.1$ vs. $26.0 \pm 0.2 \mathrm{~g} \%)(P<0.001)$, compared with WR. HFWR was found to be of medium GI $(61.3 \pm 2.8)$, whereas WR was of high GI (79.2 \pm 4.8$)$. Overall, HFWR had 23\% lower GI compared with WR $(P=0.002)$.

Conclusions: The new HFWR variety can be considered as a potentially healthier alternative to commercial WR in rice-eating populations, on account of its lower GI and high fiber content.
\end{abstract}

\section{Introduction}

$\mathbf{N}$ ONCOMMUNICABLE DISEASES SUCH AS type 2 diabetes and cardiovascular disease currently represent the leading cause of morbidity and mortality throughout the world, including developing countries, where communicable diseases had hitherto held sway. ${ }^{1}$ The explosive increase in noncommunicable diseases in developing countries has been attributed to changes in diet and physical activity levels wrought by economic development, industrialization, and urbanization. ${ }^{2}$ Among dietary factors, the role of dietary carbohydrates, particularly the quantity and quality of the staple cereal, has received widespread attention with respect to risk of noncommunicable diseases.

The Glycemic Index (GI) of a food (reflecting the relative rate of digestibility of the available carbohydrates of the food compared with a reference food [usually glucose] ${ }^{4}$ is an important measure of the quality of carbohydrate. ${ }^{5}$ Diets high in GI have been shown to increase the risk for chronic diseases like cardiovascular disease and type 2 diabetes because

\footnotetext{
${ }^{1}$ Department of Diabetology, Madras Diabetes Research Foundation, Chennai, Tamil Nadu, India.

${ }^{2}$ Department of Foods Nutrition \& Dietetics Research, Madras Diabetes Research Foundation, Chennai, Tamil Nadu, India.

${ }^{3}$ Clinical Nutritional Sciences, Singapore Institute for Clinical Sciences, Brenner Centre for Molecular Medicine, Singapore.

This study was registered with the Clinical Trial Registry of India with clinical trial registration number CTRI REF/2015/05/009035.
}

(C) Viswanathan Mohan, et al., 2016; Published by Mary Ann Liebert, Inc. This Open Access article is distributed under the terms of the Creative Commons Attribution Noncommercial License (http://creativecommons.org/licenses/by-nc/4.0/) which permits any noncommercial use, distribution, and reproduction in any medium, provided the original author(s) and the source are credited. 
of their impact on blood glucose and insulin levels. ${ }^{6,7}$ In contrast, low GI diets have several health benefits such as decreasing plasma glucose levels, plasma insulin demand, and levels of inflammatory markers. ${ }^{8-10}$

Rice (Oryza sativa) is the staple food of more than half of the world's population (mainly the Asia Pacific region and some parts of the Americas and Africa) and provides $20 \%$ of the world's dietary calorie supply. ${ }^{11}$ Most of the rice consumed today is in the form of refined white rice (WR), which consists almost wholly of the endosperm (90\% starch) and is virtually devoid of bran and germ, ${ }^{12}$ with less than $1 \%$ dietary fiber (DF). ${ }^{13}$ Use of high GI refined $\mathrm{WR}^{14,15}$ has been shown to be associated with the metabolic syndrome and type 2 diabetes in cross-sectional and longitudinal studies in several western and Asian populations. ${ }^{16-19}$

Use of whole grains such as brown rice, which contains not only more DF but also micro- and phytonutrients, would appear to be a healthier alternative to reduce the glycemic response and thus the risk of type 2 diabetes and other noncommunicable diseases. ${ }^{2,8}$ Unfortunately, consumer awareness regarding the health benefits of brown rice is low, and it suffers from certain limitations like poor shelf life, longer cooking time, and poor sensory attributes compared with $\mathrm{WR}^{20,21}$ Therefore development of a rice variety with high amounts of DF and lower GI, but retaining the consumerfriendly characteristics of WR, is the need of the hour.

We therefore attempted, in collaboration with agricultural scientists from South India, to identify WR varieties with improved glycemic profiles using advances in agriculture and biotechnology. Our efforts have culminated in the discovery of a novel high-fiber WR (HFWR) variety with improved nutritional and glycemic properties. The present study reports on the GI of the HFWR and compares it with that of commercially available WR.

\section{Materials and Methods}

\section{Development of a new high-fiber rice variety}

The high-fiber rice variety was developed after 5 years of research by using classical "marker assisted" plant breeding for introgression of various mutations and biochemical screening approaches, and a patent for the methodology used to prepare the rice has been applied for (application number 3126/CHE/2013). The popular South Indian rice variety Ponni was chosen as the starting point. The breeding program did not involve the use of genetic engineering/gene transformation technologies. We tried to increase the DF by raising the nondigestible starch (resistant starch [RS]) content of rice grains, through structural modification of amylopectin by deploying a set of induced mutations leading to downregulation of enzymes necessary for chain length extension of amylopectin in the rice endosperm. The resulting enhancement of DF mainly as RS was unaffected by subsequent polishing and also did not affect the cooking quality.

The HFWR was also tested over three seasons across three location to assess the variability of RS content due to soil conditions and agricultural practices, and no significant differences were found in its composition. The GI of HFWR was tested during two different harvest periods-after the first harvest (Kharif) in 2013 and after the second harvest (Rabi) in 2014. The commercial WR used as a control was of the Ponni rice lineage during both the GI studies.

\section{Food composition analysis}

The macronutrient composition and available carbohydrate content were determined in triplicates using the 2000 AACC standard ${ }^{22}$ and enzymatic kit methods (Megazyme International, Bray, County Wicklow, Ireland), respectively. The amylose content was measured using the International Organization for Standardization ISO 6647 method. ${ }^{23}$ The RS content was estimated using the Megazyme kit method (adapted from the 2002 AOAC standard). ${ }^{24}$ The total DF was estimated using the AOAC 991.43 standard. $^{25}$

\section{Participants}

Thirty healthy volunteers between 18 and 45 years of age were recruited from the volunteer registry for the GI study of HFWR in 2013. In the year 2014, GI testing of the second harvest HFWR was done in a subsample of 15 healthy volunteers. A randomized controlled crossover study design was used in both the trials. Participants were excluded if they were under-/overweight, not willing to participate in the study, or on any special diet, had any family history of diabetes, were suffering from acute or chronic illness, had any food allergies, or were on any medications (Fig. 1). Anthropometric measurements including height, weight, and waist circumference were taken in the fasting state using standardized techniques as described elsewhere. ${ }^{26}$

\section{Ethical considerations}

Participants were given full details of the study protocol and the opportunity to ask questions. All gave written informed consent before participation. The study was conducted according to the guidelines laid down in the Declaration of Helinski and was approved by the Institutional Ethics Review Committee of Madras Diabetes Research Foundation, Chennai, India.

\section{Study protocol}

This study was conducted using the internationally recognized GI protocol ${ }^{3}$ recommended by the Food and Agriculture Organization/World Health Organization ${ }^{4}$ in 1998, which has been validated in an interlaboratory study. ${ }^{27}$

Volunteers visited the GI Testing Centre of the Madras Diabetes Research Foundation on the test day in the morning after a 10-12-h overnight fast. An interviewer elicited details regarding meals over the previous $24 \mathrm{~h}$, physical activity, smoking, alcohol, and consumption of caffeine-containing drinks using a validated questionnaire and ensured that the volunteers maintained their usual diet and physical activity schedules (Supplementary Tables S1 and S2; Supplementary Data are available online at www.liebertonline.com/dia) and refrained from smoking and alcohol during the study period. The participants were informed about the study foods beforehand, and informed consent was taken from them prior to starting the study. Participants were randomized using computer-generated randomized tables and were given the test food accordingly. The reference food trial was performed at the first, last, and middle of the sequence of the test foods.

\section{Test and reference food}

HFWR and WR diets providing $50 \mathrm{~g}$ of available carbohydrate (63.6 g of uncooked rice) were given as test foods. Fiftyfive grams of dextrose (glucose monohydrate) dissolved in 


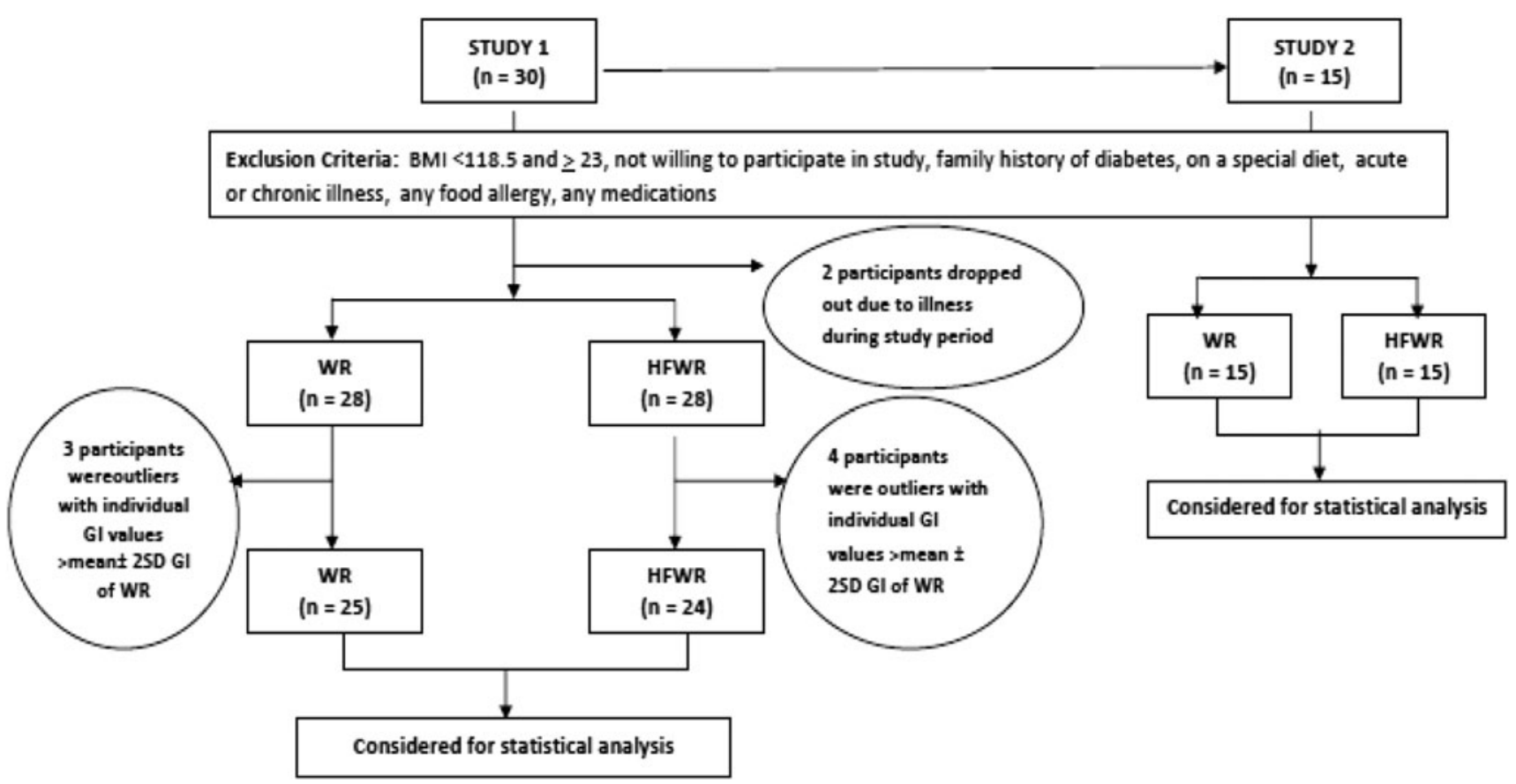

FIG. 1. Participant flow diagram. BMI, body mass index; GI, glycemic index; HFWR, high-fiber white rice; WR, white rice.

$200 \mathrm{~mL}$ of water was used as the reference food [Glucon- ${ }^{\circledR}$ glucose powder; Heinz India (P) Ltd., Mumbai, India]. The pressure cooking method was used for the test food preparation as this is the most popular and conventional method used in this population. Uncooked rice providing $50 \mathrm{~g}$ of available carbohydrate (HFWR, $67 \mathrm{~g}$; WR, $65 \mathrm{~g}$ ) was used (rice-to-water ratio of 1:2) for common WR and HFWR. The rice was pressurecooked (three whistles), and cooking time for WR and HFWR was 30 and $32 \mathrm{~min}$, respectively. The test food recipe was standardized in the in-house test kitchen during each GI testing. Volunteers were given $200 \mathrm{~mL}$ of water along with the test food, and an extra $200 \mathrm{~mL}$ was given during the subsequent $2 \mathrm{~h}$.

\section{Blood glucose measurement}

All participants underwent 3 days of testing with the reference food and 2 days with the test food in random order with at least a 2-day gap between measurements so as to minimize carryover effects. Blood glucose was measured using the HemoCue ${ }^{\circledR}$ Glucose $201^{+}$analyzer (HemoCue Ltd., Ängelholm, Sweden) and an automatic lancet device (AccuChek $^{\circledR}$ sensor; Roche Diagnostics GmbH, Mannheim, Germany). Participants were encouraged to warm their hands to increase the blood flow, prior to the administration of the finger prick.

The fasting capillary blood sample was obtained before consumption of the food. Volunteers immediately consumed the reference/test food containing $50 \mathrm{~g}$ of available carbohydrate. The first sip or bite was set as time 0 , and blood samples were taken at $15,30,45,60,90$, and $120 \mathrm{~min}$.

\section{Calculation of the $\mathrm{Gl}$}

In total, 30 participants were recruited, of whom two individuals dropped out of the first study. Additionally, four participants in the HFWR rice group and three in the WR group whose GI was greater than the mean \pm 2 SD were considered as outliers and excluded. Hence data of 24 and 25 volunteers for the HFWR and WR groups, respectively, were included in the GI analysis for the first harvest GI testing study. For the second harvest GI testing study, all the 15 participants were included in the analysis.

The incremental area under the curve (IAUC) values of the blood glucose test and reference foods were calculated geometrically using the trapezoid rule, ignoring the area below the fasting baseline. ${ }^{1}$ The mean and SEM values of the IAUC for the reference and test food were calculated. The GI value was calculated with the following equation, and the mean of the resulting value was the GI of the test food:

$$
\begin{aligned}
& \text { GI value of test food }(\%) \\
& =\frac{\text { Blood value IAUC value for test food }}{\text { IAUC value of reference food }} \times 100
\end{aligned}
$$

\section{Statistical analysis}

Statistical analysis was performed using SPSS software (version 20.0; SPSS, Inc., Chicago, IL). Data are given as means with their SEs. The significance of differences in GI and in IAUC of HFWR and WR was tested using the MannWhitney $\mathrm{U}$ test $(t$ test). Using linear regression, the effects of age, sex, body mass index, and waist circumference on the GI and IAUC were analyzed for the test foods. Statistical significance was set at $P<0.05$.

\section{Results}

The nutrient compositions of the newly developed HFWR and WR are shown in Table 1 . The available carbohydrate, protein, and fat content were significantly lower in HFWR compared with WR $(P<0.001)$. The total DF content of 
Table 1. Nutrient Composition of High-Fiber White Rice and White Rice

\begin{tabular}{lccc}
\hline & \multicolumn{2}{c}{ Raw } & \\
\cline { 2 - 3 } Nutrient & $H F W R$ & $W R$ & P value \\
\hline Moisture (g) & $11.0 \pm 0.5$ & $10.0 \pm 0.6$ & 0.05 \\
Available carbohydrate (g) & $75.1 \pm 0.9$ & $77.1 \pm 0.6$ & $<0.001$ \\
Protein (g) & $8.0 \pm 0.1$ & $9.4 \pm 0.2$ & $<0.001$ \\
Fat (g) & $0.3 \pm 0.04$ & $0.8 \pm 0.1$ & $<0.001$ \\
Ash (g) & $0.7 \pm 0.04$ & $0.4 \pm 0.01$ & $<0.001$ \\
Total dietary fiber (g) & $8.0 \pm 0.1$ & $1.58 \pm 0.2$ & $<0.001$ \\
Resistant starch (g) & $3.9 \pm 0.2$ & $0.6 \pm 0.03$ & $<0.001$ \\
Amylose (g) & $32.8 \pm 1.1$ & $26.0 \pm 0.2$ & $<0.001$ \\
\hline
\end{tabular}

Values are for $100 \mathrm{~g}$ of uncooked rice.

${ }^{a}$ The Mann-Whitney U test was used to test significance. $P<0.05$ was considered to be statistically significant.

${ }^{\mathrm{b}}$ Dietary fiber inclusive of resistant starch.

HFWR, high-fiber white rice; WR, white rice.

HFWR was fivefold higher ( $8.0 \pm 0.1$ vs. $1.58 \pm 0.17 \mathrm{~g} \%)$, RS content was 6.5 -fold higher $(3.9 \pm 0.2$ vs. $0.6 \pm 0.03 \mathrm{~g} \%)$ $(P<0.001)$, and the amylose content was significantly higher $(32.8 \pm 1.1$ vs. $26.0 \pm 0.2 \mathrm{~g} \%)(P<0.001)$, compared with WR.

The GI of HFWR and WR was estimated twice-first among 30 healthy participants in the year 2013 and then in a subsample of 15 participants in the year 2014 (Table 2). The average body mass index of the study participants was $22.3 \pm 0.5$ and $20.6 \pm 0.4 \mathrm{~kg} / \mathrm{m}^{2}$ for Studies 1 and 2, respectively. Age, sex, body mass index, and waist circumference did not differ significantly between the study groups. There was no significant difference in the macronutrient consumption and physical activity levels of the study participants (Supplementary Tables S1 and S2).

The mean IAUC and GI of HFWR and WR are shown in Table 3 and Figure 2. The HFWR showed medium GI in both the studies with no significant differences in the mean IAUC $(2,943 \pm 296$ vs. $2,989 \pm 394 \mathrm{mg} \times \mathrm{min} / \mathrm{dL} ; P=0.84)$ or GI (59.4 \pm 3.6 vs. $64.4 \pm 4.4 ; P=0.28$ ) between the two studies done 1 year apart. Similarly, the GI of WR did not differ significantly between the two studies $(80.6 \pm 6.5$ vs. $77.0 \pm 7.6$; $P=0.81$ ). Taking the average of Studies 1 and 2, HFWR was

Table 2. Demographic/Anthropometric Characteristics of Participants in the Two Glycemic Index Studies

\begin{tabular}{lccc}
\hline Characteristic & $\begin{array}{c}\text { Study 1, 2013 } \\
(\mathrm{n}=25)\end{array}$ & $\begin{array}{c}\text { Study 2, 2014 } \\
(\mathrm{n}=15)\end{array}$ & P value $^{\mathrm{a}}$ \\
\hline Female $[n(\%)]^{\mathrm{b}}$ & $12(48)$ & $8(53.3)$ & 0.45 \\
Age $(\text { years })^{\mathrm{c}}$ & $27.9 \pm 0.9$ & $26.7 \pm 1.0$ & 0.83 \\
$\mathrm{BMI}\left(\mathrm{kg} / \mathrm{m}^{2}\right)^{\mathrm{c}}$ & $22.3 \pm 0.5$ & $20.6 \pm 0.4$ & 0.06 \\
Waist circumference $(\mathrm{cm})^{\mathrm{c}}$ & & \\
$\quad$ Male & $83.0 \pm 1.7$ & $80 \pm 1.9$ & 0.40 \\
Female & $73.6 \pm 1.7$ & $68.1 \pm 1.5$ & 0.12 \\
\hline
\end{tabular}

\footnotetext{
${ }^{\text {a }}$ Significance was tested using the Mann-Whitney $U$ test for continuous variables and the $\chi^{2}$ test for categorical variables. $P<0.05$ was considered significant.

${ }^{\mathrm{b}}$ Number of participants (percentage female).

${ }^{c}$ Data are mean \pm SD values.

BMI, body mass index.
}

categorized under the medium GI category $(61.3 \pm 2.8)$, and its GI was found to be $23 \%$ lower $(P=0.004)$ compared with WR (79.2 \pm 4.8$)$, which was classified as high GI. The IAUC of the HFWR $(2,961 \pm 231 \mathrm{mg} \times \mathrm{min} / \mathrm{dL})$ was also lower than the WR $(3,370 \pm 226 \mathrm{mg} \times \mathrm{min} / \mathrm{dL} ; P=0.009)$.

\section{Discussion}

We report here on the development of a unique HFWR variety that has significantly higher DF and lower GI even after polishing. The present study has followed the internationally recognized GI protocol ${ }^{3}$ recommended by the Food and Agriculture Organization/World Health Organization ${ }^{4}$ in 1998 and validated by Henry et al. ${ }^{27}$ in 2008 . The new HFWR showed 23\% lower GI compared with the control Ponni WR. We believe that widespread adoption of HFWR can help to improve the health of populations, by enhancing the quality of the staple dietary cereal.

Several factors influence the GI of foods, including processing, preparation, and cooking methods, the physical form of the food, the type of sugars and starch in the food, and other factors such as the presence of DR and antinutrients and the ripeness or maturity of the food. ${ }^{28}$ The medium GI of our HFWR may be attributed to the high DF content of this rice, which was fivefold higher than that of WR. The high DF of HFWR may be due to its high amylose and long-chain amylopectin content, which in turn results in high RS. ${ }^{29}$ The glucose chains of amylose starch are more bound to each other by $\mathrm{H}^{+}$bonds, making them less available for amylitic attack compared with amylopectin, which has many branched chains and larger surface area. ${ }^{30}$ Although two earlier developed mutant WR specimens from Japonica varieties in Korea also reported high fiber and amylose content $(4.8 \mathrm{~g} \%$ fiber and $33.96 \mathrm{~g} \%$ amylose), they were not commercially successful because of the poor gelatinization, low swelling ability, and increased hardness. ${ }^{31,32}$ Our HFWR appears more promising in this respect.

The ability of DF to reduce the glucose response of food is related to induction of satiety-related hormones like glucagon-like peptide-1, ghrelin, leptin, gastric inhibitory polypeptide, and peptide $\mathrm{YY} .{ }^{4,33} \mathrm{DF}$ induces production of short-chain fatty acids, which act as a external energy source and increase the secretion of satiety-related hormones via G-protein-coupled receptors from the L-cells. These hormones bring about a decrease in postprandial glucose and insulin responses. ${ }^{34}$

Earlier attempts at developing and testing high-fiber rice varieties have shown mixed results. Yusof et al. ${ }^{35}$ estimated the GI of commercially available brown rice, WR, and highfiber rice in 10 healthy individuals in Malaysia. This study, surprisingly, showed that both WR and high-fiber rice were in the high GI category ( 81 and 87 , respectively). Although no description of the high-fiber rice was provided, the rice apparently needed to be cooked for longer duration (35 and $40 \mathrm{~min}$ ), which might have possibly led to higher degree of gelatinization, eliciting higher GI responses despite the higher fiber content.

Rapid industrial development and urbanization have led to increase in consumption of processed and refined foods, such as highly polished WR, which are low in DF and high in GI and are thus detrimental to health. This is more alarming in some ethnic groups like South Asians who have an increased 
Table 3. Mean Incremental Area Under the Curve and Glycemic Index of High-Fiber White Rice and White Rice

\begin{tabular}{|c|c|c|c|c|c|c|c|c|c|}
\hline & \multicolumn{3}{|c|}{$H F W R$} & \multicolumn{3}{|c|}{$W R$} & \multicolumn{3}{|c|}{ Average of the two studies } \\
\hline & Study 1 & Study 2 & $\mathrm{P}$ value $\mathrm{a}^{\mathrm{a}}$ & Study 1 & Study 2 & $\mathrm{P}$ value ${ }^{\mathrm{a}}$ & $H F W R$ & $W R$ & $\mathrm{P}$ value $\mathrm{a}^{\mathrm{a}}$ \\
\hline $\begin{array}{l}\text { Number of } \\
\text { participants }\end{array}$ & 24 & 15 & - & 25 & 15 & - & 39 & 40 & \\
\hline $\begin{array}{l}\text { IAUC } \\
\quad(\text { mean } \pm \text { SEM })\end{array}$ & $2,943 \pm 296$ & $2,989 \pm 394$ & 0.84 & $3,383 \pm 298$ & $3,346 \pm 380$ & 0.933 & $2,961 \pm 231$ & $3,370 \pm 226$ & $0.009^{\mathrm{b}}$ \\
\hline GI $($ mean \pm SEM $)$ & $59.4 \pm 3.6$ & $64.4 \pm 4.4$ & 0.283 & $80.6 \pm 6.5$ & $77.0 \pm 7.6$ & 0.812 & $61.3 \pm 2.8$ & $79.2 \pm 4.8$ & 0.004 \\
\hline GI category & Medium & Medium & & High & High & & Medium & High & \\
\hline
\end{tabular}

Glucose was defined as having a reference Glycemic Index (GI) of 100.

${ }^{a}$ Significance was tested using the Mann-Whitney U test. $P<0.05$ was considered significant.

${ }^{\mathrm{b}}$ Adjusted with reference (glucose) incremental area under the curve (IAUC).

HFWR, high-fiber white rice; WR, white rice.

susceptibility to insulin resistance and diabetes and who derive nearly $70 \%$ of their total calories from these food sources. ${ }^{36}$

Brown rice, being a whole grain (unpolished), has a DF of $5.3 \mathrm{~g} \% .{ }^{13}$ Our rice (HFWR), despite being polished WR, showed a DF content of $8.1 \mathrm{~g} \%$, mainly as nondigestible starch and some remnant bran constituents. However, HFWR, being a WR, may not contain bran micro- and phytonutrients as in brown rice. ${ }^{37}$

The International GI table ${ }^{38}$ shows a wide range of GI for brown rice, from 45 to 87 , falling into all the three GI categories (low, <55; medium, >55-69; and high, $>70$; on a scale of 100 being the GI of glucose), which may be due to the varietal differences and processing methods. In total, 12 different brown rice varieties with low to medium GI values, including pregerminated, parboiled, and steamed processed rice, were reported in the International GI table. Despite such GI values, brown rice has several challenges for its practical use. This includes poor consumer acceptance, as it is per- ceived as being an inferior quality of rice due to its color and sensory properties. Moreover, there are problems associated with short shelf life ${ }^{20}$ and longer cooking time.

HFWR not only has an inherent high DF and a lower GI (which is similar to brown rice), but it is also indistinguishable from WR with respect to sensory properties. Therefore it is not surprising that HFWR has gained wide acceptance, as is evident from its widespread availability in supermarkets across South India. Our HFWR is likely to be of benefit not only to consumers in India, but also to those in countries such as China, Japan, Korea, and other nations where rice is consumed as a staple. These countries make up more than $70 \%$ of the world's population and nearly the same proportion of the world's people with diabetes. Use of HFWR has the potential to improve the health of people in this region by improving the quality of the diet due to the beneficial effects of higher fiber content and lower GI.

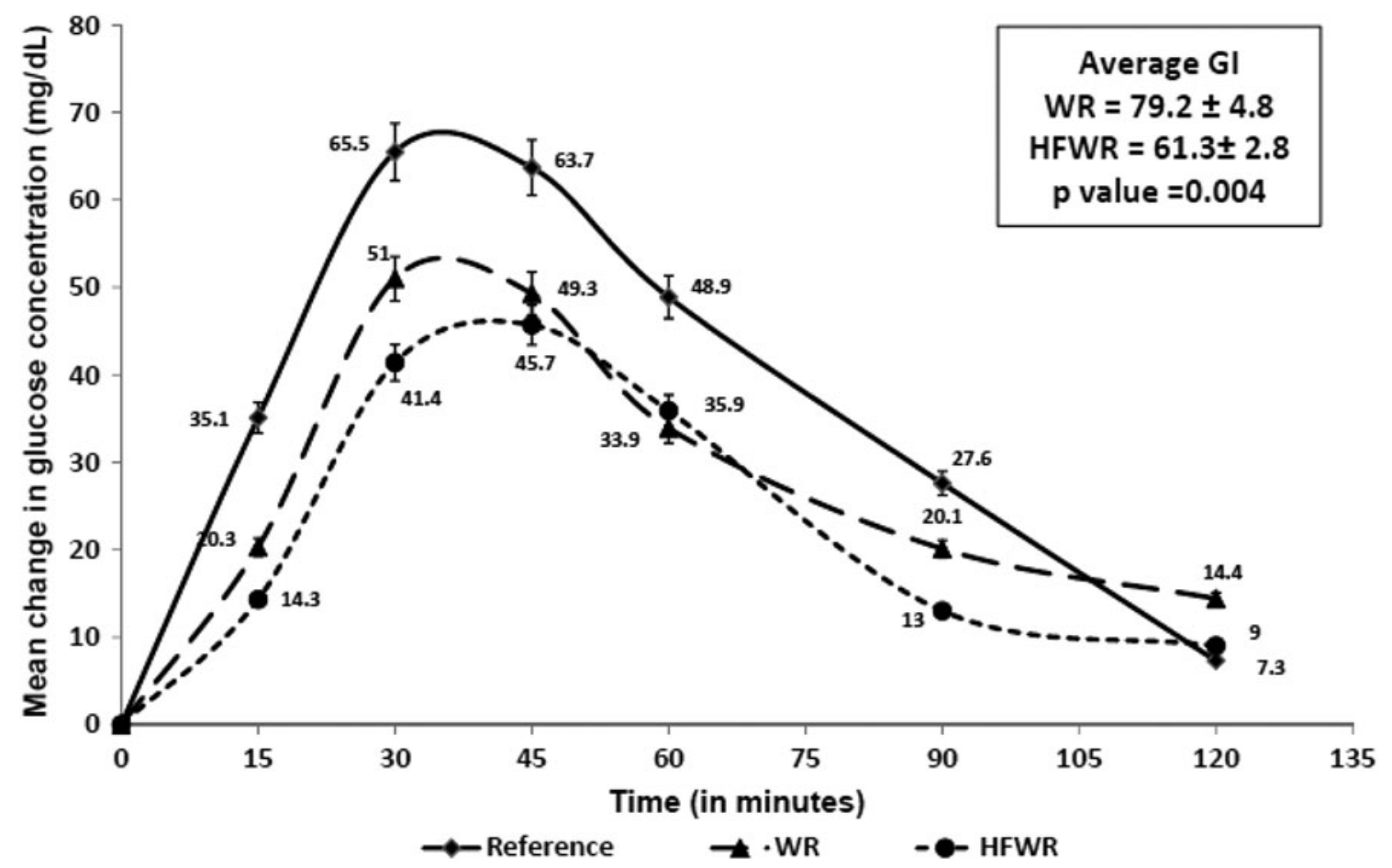

FIG. 2. Mean blood glucose response of test food high-fiber white rice (HFWR) (circles) and white rice (WR) (triangles) compared with glucose (reference) (diamonds). GI, Glycemic Index. 
This study has several strengths. First, an international standardized GI analysis method was used to study the glycemic properties of the HFWR. Second, the testing was done in successive years to rule out seasonal variations. The novelty of the HFWR is another significant strength. The small sample size and short duration of the study are the limitations of the study.

\section{Conclusions}

We report on a newly developed HFWR that has lower GI and excellent sensory and other characteristics comapred with WR. Switching from the current high GI WR to HFWR could help to reduce overall dietary GI and the glycemic load. Further studies on HFWR for its physicochemical and structural properties to correlate with its glycemic properties are underway. The health implications in the prevention and control of chronic diseases like diabetes, obesity, and cardiovascular diseases are obvious. However, long-term supplementation trials are needed to see its potential metabolic benefit, such as its effects on serum lipids and other metabolic markers.

\section{Acknowledgments}

The authors acknowledge Dr. Mohan's Health Care Products Pvt. Ltd., Chennai, India, for sponsoring the study and their collaboration partner TEXCITY Biosciences Coimbatore for cultivating high-fiber rice.

\section{Author Disclosure Statement}

No competing financial interests exist.

\section{References}

1. World Health Organization: Global Status Report on Non Communicable Diseases. 2014. www.who.int/nmh/publications/ ncd-status-report-2014/en/ (accessed September 4, 2015).

2. Ley SH, Hamdy O, Mohan V, et al.: Prevention and management of type 2 diabetes: dietary components and nutritional strategies. Lancet 2014;383:1999-2007.

3. Brouns F, Bjorck I, Frayn KN, et al.: Glycaemic index methodology. Nutr Res Rev 2005;18:145-171.

4. Food and Agriculture Organization/World Health Organization: Carbohydrates in Human Nutrition: Report of Joint FAO/WHO Expert Consultation. FAO Food Nutr Paper 1998;66:1-140.

5. Jenkins DJ, Wolever TM, Taylor RH, et al.: Glycemic index of foods: a physiological basis for carbohydrate exchange. Am J Clin Nutr 1981;34:362-366.

6. Liu S, Willett WC, Stampfer MJ, et al.: A prospective study of dietary glycemic load, carbohydrate intake, and risk of coronary heart disease in US women. Am J Clin Nutr 2000; 71:1455-1461.

7. Mohan V, Radhika G, Vijayalakshmi P, et al.: Can the diabetes/cardiovascular disease epidemic in India be explained, at least in part, by excess refined grain (rice) intake? Indian J Med Res 2010;131:369-372.

8. Sun Q, Spiegelman D, van Dam RM, et al.: White rice, brown rice, and risk of type 2 diabetes in US men and women. Arch Intern Med 2010;170:961-969.
9. Ludwig DS: The glycemic index: physiological mechanisms relating to obesity, diabetes, and cardiovascular disease. JAMA 2002;287:2414-2423.

10. Wolever TMS, Gibbs AL, Mehling C, et al.: The Canadian trial of Carbohydrates in Diabetes (CCD), a 1-y controlled trial of low-glycemic-index dietary carbohydrate in type 2 diabetes: no effect on glycated hemoglobin but reduction in C-reactive protein. Am J Clin Nutr 2008;87:114-125.

11. Food and Agriculture Organization: Rice Is Life. 2004. www.fao.org/rice2004/en/f-sheet/factsheet3.pdf (accessed July 20, 2015).

12. Juliano BO: Rice in Human Nutrition. Rome: International Rice Research Institute in collaboration with Food and Agriculture Organization, 1993:35-61.

13. Shobana S, Malleshi NG, Sudha V, et al.: Nutritional and sensory profile of two Indian rice varieties with different degrees of polishing. Int J Food Sci Nutr 2011;62:800-810.

14. Shobana S, Kokila A, Lakshmipriya N, et al.: Glycaemic index of three Indian rice varieties. Int J Food Sci Nutr 2012;63:178-183.

15. Kaur B, Ranawana V, Henry CJK: The glycaemic index of rice and rice products: a review, and table of GI values. Crit Rev Food Sci Nutr 2015 January 15 [Epub ahead of print]. doi: 10.1080/10408398.2012.717976.

16. Bhupathiraju SN, Tobias DK, Malik VS, et al.: Glycemic index, glycemic load, and risk of type 2 diabetes: results from 3 large US cohorts and an updated meta-analysis. Am J Clin Nutr 2014;100:218-232.

17. Radhika G, Van Dam RM, Sudha V, et al.: Refined grain consumption and the metabolic syndrome in urban Asian Indians (CURES 57). Metabolism 2009;58:675-681.

18. Radhika G, Ganesan A, Sathya RM, et al.: Dietary carbohydrates, glycemic load and serum high-density lipoprotein cholesterol concentrations among South Indian adults. Eur J Clin Nutr 2009;63:413-420.

19. Mohan V, Radhika G, Sathya RM, et al.: Dietary carbohydrates, glycaemic load, food groups and newly detected type 2 diabetes among urban Asian Indian population in Chennai, India (Chennai Urban Rural Epidemiology Study 59). Br J Nutr 2009;9:1-9.

20. Kumar S, Mohanraj R, Sudha V, et al.: Perceptions about varieties of brown rice: a qualitative study from Southern India. J Am Diet Assoc 2011;111:1517-1522.

21. Sudha V, Spiegelman D, Hong B, et al.: Consumer Acceptance and Preference Study (CAPS) on brown and undermilled Indian rice varieties in Chennai, India. J Am Coll Nutr 2013;32:50-57.

22. AACC: Approved Methods of the American Association of Cereal Chemists, $11^{\text {th }}$ Ed. http://methods.aaccnet.org/toc .aspx (accessed June 20, 2015).

23. International Organization for Standardization: ISO 66472, Rice-Determination of Amylose Content-Part 2: Routine Method. www.iso.org/iso/catalogue_detail.htm? csnumber $=57294$ (accessed July 15, 2015).

24. McCleary BV, McNally M, Rossiter P: Measurement of resistant starch by enzymatic digestion in starch and selected plant materials: collaborative study. J AOAC Int 2002;85:1103-1111.

25. AOAC: AOAC Official Method 991.43 Total, Soluble, and Insoluble Dietary Fibre in Foods. http://acnfp.food.gov.uk/ sites/default/files/mnt/drupal_data/sources/files/multimedia/ pdfs/annexg.pdf (accessed June 20, 2015).

26. Deepa M, Pradeepa R, Rema M, et al.: The Chennai Urban Rural Epidemiology Study (CURES) - study design and 
methodology (urban component) (CURES-1). J Assoc Physicians India 2003;51:863-870.

27. Henry CJK, Lightowler HJ, Newens K, et al.: Glycemic index of common foods tested in the $\mathrm{UK}$ and India. Br J Nutr 2008;99:840-845.

28. Nord T: Glycemic Index from Research to Nutrition Recommendations? Copenhagen: Nordic Council of Ministers, 2005:21-22.

29. Trinidad TP, Mallillin AC, Encabo RR, et al.: The effect of apparent amylose content and dietary fibre on the glycemic response of different varieties of cooked milled and brown rice. Int J Food Sci Nutr 2013;64:89-93.

30. Fatema K, Rahman F, Sumi N, et al.: Glycemic index of three common varieties of Bangladeshi rice in healthy subjects. Afr J Food Sci 2010;4:531-535.

31. Lee KW, Song KE, Lee HS, et al.: The effects of Goami No. 2 rice, a natural fiber-rich rice, on body weight and lipid metabolism. Obesity (Silver Spring) 2006;14:423430.

32. Kang HJ, Hwang IK, Kim KS, et al.: Comparative structure and physicochemical properties of Ilpumbyeo, a highquality japonica rice, and its mutant, Suweon 464. J Agric Food Chem 2003;51:6598-6603.

33. Higgins JA: Resistant starch and energy balance: impact on weight loss and maintenance. Crit Rev Food Sci Nutr 2014;54:1158-1166.

34. Souza da Silva C, Haenen D, Koopmans SJ, et al.: Effects of resistant starch on behaviour, satiety-related hormones and metabolites in growing pigs. Animal 2014;8:14021411.

35. Yusof BNM, Talib RA, Karim NA: Glycaemic index of eight types of commercial rice in Malaysia. Malay J Nutr 2005;11:151-163.

36. Unnikrishnan R, Anjana RM, Mohan V: Diabetes in South Asians: is the phenotype different? Diabetes 2014;63: 53-55.

37. Panlasigui LN, Thompson LU: Blood glucose lowering effects of brown rice in normal and diabetic subjects. Int $\mathbf{J}$ Food Sci Nutr 2006;57:151-158.

38. Atkinson FS, Foster-Powell K, Brand-Miller JC: International tables of glycemic index and glycemic load values. Diabetes Care 2008;31:2281-2283.

Address correspondence to: Viswanathan Mohan, MD, FRCP, PhD, DSc Department of Diabetology Madreas Diabets Research Foundation \& Dr. Mohan's Diabetes Specialities Centre WHO Collaborating Centre for Non-Communicable Diseases International Diabetes Federation Centre of Education 4, Conran Smith Road Gopalapuram, Chennai-600 086, India

E-mail: drmohans@diabetes.ind.in Web site: www.drmohandiabetes.com 